\title{
Real-time detection of the aluminium contribution during laser welding of Usibor1500 tailor-welded blanks
}

\author{
J. Mirapeix ${ }^{12}$, E. Vila ${ }^{3}$, J. J. Valdiande ${ }^{12}$, A. Riquelme ${ }^{4}$, M. Garcia ${ }^{3}$, A. Cobo ${ }^{1}$ \\ ${ }^{1}$ Photonics Engineering Group, Universidad de Cantabria, Santander (Spain) \\ ${ }^{2}$ SADIQ Engineering S.L., Santander (Spain) \\ ${ }^{3}$ AUTOTECH ENGINEERING, A.I.E (Gestamp), Sant Esteve Sesrovires, Barcelona
}

(Spain)

${ }^{4}$ SOLBLANK (Gestamp), Castellbisbal, Barcelona (Spain)

*Corresponding author / e-mail: jesus.mirapeix@unican.es

\begin{abstract}
The identification and intensity estimation of some aluminium emission lines have been proposed to perform an on-line quantification of the $\mathrm{Al}$ contribution to the laser-welding process of Usibor blanks. This boron steel is protected by an Al-Si coating that is removed by laser ablation before welding. If this process fails to remove $\mathrm{Al}$ from the joint surface, its contribution may affect the final properties of the resulting seams, therefore compromising their quality. Experimental tests have been performed, some of them in a real production scenario. They have been analysed and compared to the results of welding test specimens, analysis of the associated tensile properties and fracture locations and seam macrographs. These studies have indicated that on-line quantification of the $\mathrm{Al}$ contribution to the process is feasible and that a correlation can be established between the $\mathrm{Al}$ content estimated in real-time and the results derived from the off-line tests considered.
\end{abstract}


Keywords: optical fiber sensor; on-line monitoring; plasma spectroscopy; quality assurance; laser welding; Usibor1500; tailor-welded blanks; tensile strength; macrographs

\section{Introduction}

The on-line monitoring of quality in welding processes is nowadays a key issue in different industrial scenarios. Real-time monitoring systems based on different technologies have been proposed during the last years to enable, not only a reliable and fast quality assurance, but also a better understanding of these processes. Among these proposals we can find solutions based on the monitoring of the electrical signals of the process, for example via feature extraction techniques (Zhang et al., 2014), machine vision systems that may require laser illumination and filtering (Abdullah et al., 2008) or allow the estimation of the keyhole and weld pool sizes and their correlation with the main process parameters (Zhang et al., 2015). Infrared thermography has also been used for the estimation of the weld bead width and depth of penetration in conjunction with hybrid soft computing approaches (Chandrasekhar et al., 2015) and even enabling automatic defect detection as proposed by Sreedhar et al. (2012). Jamrozik et al. (2015) proposed a hybrid solution involving analysis via machine vision in both the visible and infrared ranges with possible application to on-line welding inspection. Acoustic monitoring of the process has also been studied (Gu and Duley, 1996), in some cases considering processing by machine learning algorithms (Sumesh et al., 2015). These techniques may prove useful for some processes, but none of them enables straightforward identification and quantification of the elements participating in the process, which typically form part of the metallic alloy to be welded and the protection gas (if employed). This information can be obtained by an analysis based on plasma 
optical spectroscopy, once the emission lines found in the welding plasma spectra have been identified. This gives rise to a powerful analysis, as the process dynamics are known to be directly related to the evolution of the intensity of these lines, for example via the estimation of the plasma electronic temperature $T_{e}$ (Ferrara et al., 2000). The conventional spectroscopic monitoring solution is based on real-time detection of weld defects by means of different strategies. In recent contributions Zhang et al. (2013) defined different regions of interest within the arc-welding plasma spectra where a statistical analysis was performed and correlated to the appearance of defects; Harooni et al. (2014) proposed a defect-detection system for laser welding of Al-Mg alloys to investigate the influence of the oxide layer along the faying surface on the resulting quality. A solution based on a colorimetric analysis of the acquired plasma spectra has also been proposed (Mirapeix et al., 2014).

Plasma spectroscopy enables the contribution to the plasma emission of a given element in the joint to be identified, and even a semi-quantitative estimation of this contribution to be made. Kong et al. (2012) analyzed the evolution of $T_{e}$ profiles obtained with $\mathrm{Zn}$ and Fe lines to study the influence of the Zn coating of galvanized high-strength steels on the welding dynamics. This is precisely a key issue in the automotive industry, where Usibor1500 tailor-welded blanks are employed for different car parts. Usibor1500 is a boron steel with an Al-Si coating commonly employed in the automotive industry given its special suitability for the hot stamping process (Karbasian and Tekkaya, 2010). Hot stamping (press hardening) can be defined as a non-isothermal sheet metal forming technique where the blank is heated to around $900^{\circ} \mathrm{C}$, maintained there a specific time and then placed between cooled dies, formed and quenched at the same time (Güler, 2013). The main advantage of this technique lies in the possibility of reducing the car's weight and increasing its strength, allowing very high formability, 
forming of complex geometries and good weldability, among other features. Hot stamping and Usibor1500 blanks are typically used for the manufacturing of different car parts including: A and B pillars (Merklein et al., 2015), bumper beams, side rails and door beams (Güler, 2013). The Al-Si coating is resistant to heat and high temperature oxidation and corrosion, but it has to be removed from the joint before the welding process (Lee et al., 2014), given that the inclusion of $\mathrm{Al}$ in the seam has been proved to affect its quality, especially in terms of its tensile properties (Kang et al., 2012). Therefore it is very important to perform on-line monitoring of the aluminium contribution to the welding process: to ensure the fulfilment of quality requirements associated with the specific process considered. Some studies have been performed using laser-induced breakdown spectroscopy (LIBS) and support-vector machines (SVMs) to automatically identify the presence of $\mathrm{Al}$ in Usibor1500 blanks (Anabitarte et al., 2012). We have proposed the use of a real-time monitoring system able to perform on-line quantification of the $\mathrm{Al}$ contribution to the welding process. The use of plasma optical spectroscopy would be especially suitable for this problem.

\section{Plasma optical spectroscopy}

Provided that the light generated during welding can be captured, which is straightforward in laser and arc welding, the analysis of the acquired spectra may enable the identification of the emission lines that will appear. Figure 1 (a) depicts an example of a plasma spectrum captured during the laser-welding process of Usibor1500 tailorwelded blanks. Multiple emission lines can be observed; to identify one of them implies that the chosen line has to be associated with a particular plasma species, i.e. one of the atomic elements contributing to the process in a given ionization stage (e.g. Al I: neutral atom of aluminium). 

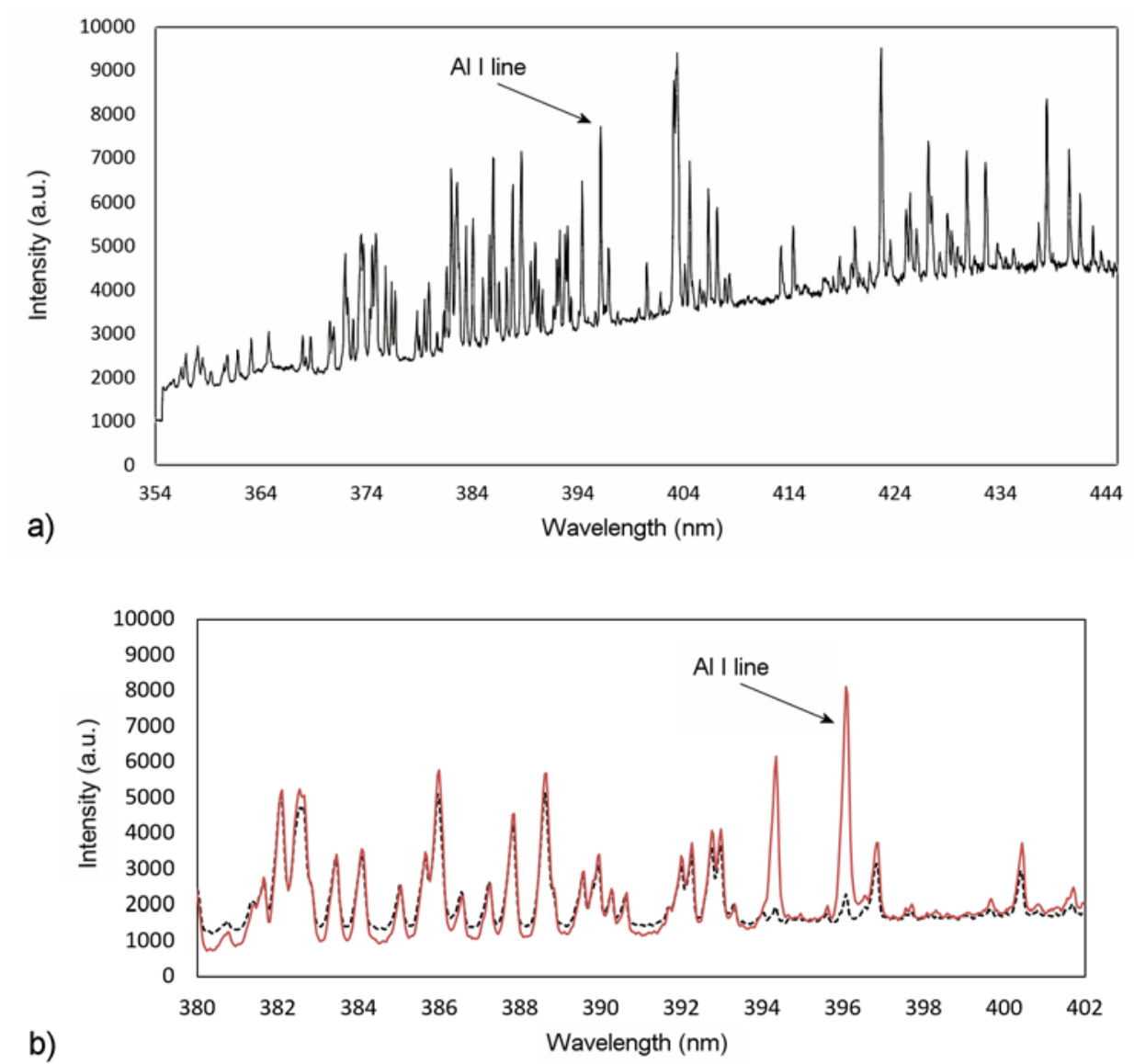

Figure 1. (a) Example of Usibor1500 spectrum captured during laser welding; (b) Comparison between spectra from laser welding of non-coated (Al-Si layer) (black dotted line) and coated Usibor1500 (red line) (the $\mathrm{Al}$ I line at $396.15 \mathrm{~nm}$ has been highlighted).

The identification of the emission lines is usually performed using a spectroscopic database (e.g. NIST atomic spectra database (Kramida et al., 2012)), taking into account their wavelengths, as each emission line exhibits a distinct wavelength related to the associated energy levels. Depending on the elements under analysis and the optical resolution of the chosen spectrometer, the unambiguous identification of a given emission line may be difficult. This problem is also found in LIBS (Laser Induced Breakdown Spectroscopy) and sophisticated approaches have been proposed by some authors: Amato et al. proposed a solution inspired in text retrieval techniques (Amato et 
al., 2010) and Gornushkin et al. designed an approach based on linear correlation (Gornushkin et al., 2009). The relative intensity or the transition probability of a given line can also be taken into account to perform a correct identification. Figure 1 (b) presents a comparison between spectra captured during laser welding of both coated and non-coated USibor15000 blanks. It can be observed that when the Al-Si coating is not considered, the Al I emission lines at 394.40 and $396.15 \mathrm{~nm}$ are almost completely suppressed in comparison to the emission lines associated with the remaining metallic and protective gas elements, thus confirming their correct identification. The low peaks that appear at these wavelengths for the non-coated spectrum can be explained by the small proportion of $\mathrm{Al}$ in the Usibor1500 base material (less than 0.015\%) (Norman et al., 2011).

The correct identification of the chosen emission lines is a key process in the estimation of the plasma electronic temperature $T_{e}$. This spectroscopic parameter was proposed as the output monitoring signal by Ferrara et al. (2000) given the correlation that could be established with the appearance of defects in the seams. This approach implies that a correct seam will exhibit a stable $T_{e}$ profile and the appearance of defects will give rise to clear changes in this signal. For monitoring purposes, $T_{e}$ has been calculated via a simplified expression involving only two emission lines associated with the same species (Ancona et al., 2001), although a more accurate estimation can be obtained by the Boltzmann-plot method. In this case, several emission lines, again belonging to the same species, have to be used as $T_{e}$ is obtained after a linear regression process (Lacroix et al., 1999). The expression that relates the intensity of a given emission line $I_{m n}$ to the population density of the upper level, $N_{m}$, is:

$$
I_{m n}=N_{m} A_{m n} h \gamma_{m n},
$$


where $A_{m n}$ is the transition probability and $h \gamma_{m n}$ is the energy of the transition. Equation (1) is important as it states that the intensity of a given emission line is directly related to the concentration of the associated element, provided that the chosen line is free from self-absorption. This can be assumed provided that the density of the emitting species (related to the concentration of that element in the sample) is low (Aragon et al., 2001). As, in this paper, we will focus on the detection and semi-quantitative estimation of $\mathrm{Al}$ (the coating layer is typically formed by $90 \% \mathrm{Al}$ and $10 \% \mathrm{Si}$, and the $\mathrm{Al}$ is only expected within the first $20 \mu \mathrm{m}$ of the material thickness, with a decreasing content within that region as the penetration (distance from the surface) increases (Kusumi et al., 2003)), the chosen $\mathrm{Al} \mathrm{I}$ line at $396.15 \mathrm{~nm}$ will be considered free from selfabsorption and local thermodynamic equilibrium (LTE) conditions will be assumed in the plasmas, as is typically assumed for laser welding processes (Ancona et al., 2001).

\section{Experimental results and discussion}

A monitoring system especially designed to estimate the $\mathrm{Al}$ contribution to the laser welding process was developed for its validation in the facilities of Solblank (Gestamp) in Castellbisbal (Barcelona, Spain). The system was formed by an optical collimator (5 mm diameter) attached to the laser welding head and oriented to the focal point of the laser beam. These input optics were connected to a $20 \mathrm{~m}$ optical fiber (300 $\mu \mathrm{m}$ core diameter) that was also attached to a CCD spectrometer chosen with an optical resolution of $0.11 \mathrm{~nm}$ and spectral range optimized in terms of obtaining the $\mathrm{Al}$ information from the plasma spectra (from 354 to $446 \mathrm{~nm}$ ). The chosen spectrometer also featured a slit width (entrance aperture) of $25 \mu \mathrm{m}$, a grating with 2400 lines $/ \mathrm{mm}$ and integration times from 1 to $65 \mathrm{~ms}$. The chosen setup implies that spatial integration of the plasma spectral information is performed, in comparison to other methods that 
perform plasma diagnostics by spatially resolving it (Aguilera and Aragon, 2002). The intensities of the emission lines considered are an average estimation of their corresponding values over the area considered by the input optics. Contributions by other authors using similar approaches for laser-welding monitoring (Sibillano et al., 2012) indicate that the data derived from different welding tests (under similar conditions) can be consistently compared.

The control of the whole system and the required processing was performed by an embedded unit specifically designed for its integration in an industrial environment. Figure 1 shows the disposition of the optical fiber attached to the laser welding head during the preliminary tests.

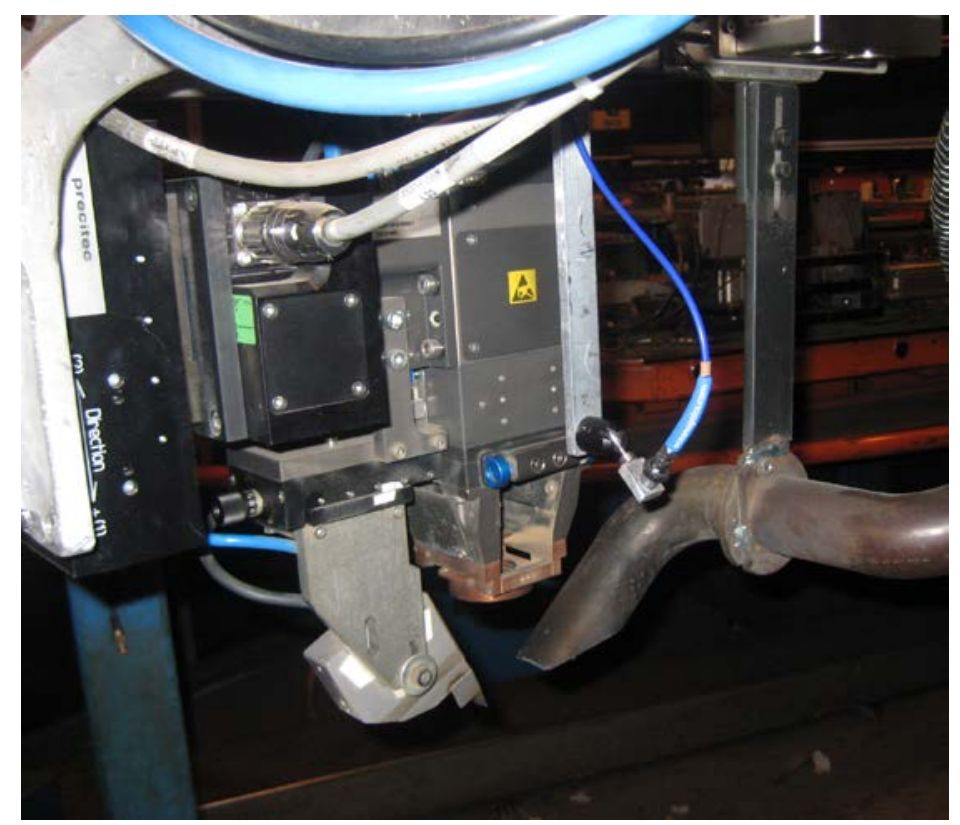

Figure 2. Detail of the laser welding head and the attached optical fiber and input optics used during the preliminary tests.

A search in a spectroscopic database (Kramida et al., 2012) regarding the Al I lines to be found in the 350 to $500 \mathrm{~nm}$ range gives rise to only 5 lines as shown in Table 1 . Taking into account different considerations, such as the vicinity of emission lines of 
other species that may generate line overlapping, the $\mathrm{Al}$ I emission line at $396.15 \mathrm{~nm}$ was selected to generate the estimation of the $\mathrm{Al}$ contribution to the process.

Table 1. Al I emission lines between 250 and 500nm

\begin{tabular}{cccc}
\hline$\lambda(\mathrm{nm})$ & Rel. Intensity & $A_{m n}\left(\mathrm{~s}^{-1}\right)$ & Accuracy \\
& & & \\
393.200 & 5 & & \\
393.568 & 4 & & \\
394.401 & 24 & $4.99 \mathrm{e}+07$ & $\leq 7 \%$ \\
396.152 & 26 & $9.85 \mathrm{e}+07$ & $\leq 7 \%$ \\
425.512 & 2 & & \\
\hline
\end{tabular}

As derived from Equation (1), the intensity of a given emission line can be directly related to the concentration of that element in the sample, in this case in the welding process. However, it would be necessary to perform a correction regarding the continuum radiation that can be observed in Figure 1. A possible solution would lie in the suppression of this background signal by means of averaging or filtering techniques (Mirapeix et al., 2008), but in this case we decided to perform an estimation based on the line-to-continuum method (Garcia-Allende et al., 2009).

$$
\frac{\varepsilon_{l}}{I_{c}}(\lambda)=2.0052 \times 10^{-5} \frac{A_{m n} g_{m}}{Z_{i}} \frac{1}{T_{e} \xi} \exp \left(\frac{E_{i}-E_{m}}{k T_{e}}\right) \frac{\lambda}{\Delta \lambda},
$$

In Equation (2) $\varepsilon_{l}$ is the line intensity integrated over the line profile, $I_{c}$ the intensity of the adjacent background radiation (non-integrated), $Z_{i}$ is the ion partition function, $\zeta$ the free-bound continuum correction, $E_{i}$ the ionization potential and $\Delta_{\lambda}$ the wavelength bandwidth. This expression allows the estimation of $T_{e}$ via an iterative method, but for monitoring the $\mathrm{Al}$ contribution, it is enough to use the ratio of the intensities of the chosen emission line and the adjacent background radiation. 
An initial test was performed in the facilities of Solblank (Gestamp) to validate the proposed solution. A set of 23 different seams was produced using Usibor1500 blanks, where the joints $(50 \mathrm{~cm}$ length) were differently pre-processed. Figure 3 shows an example of the Usibor1500 blanks used in these tests.

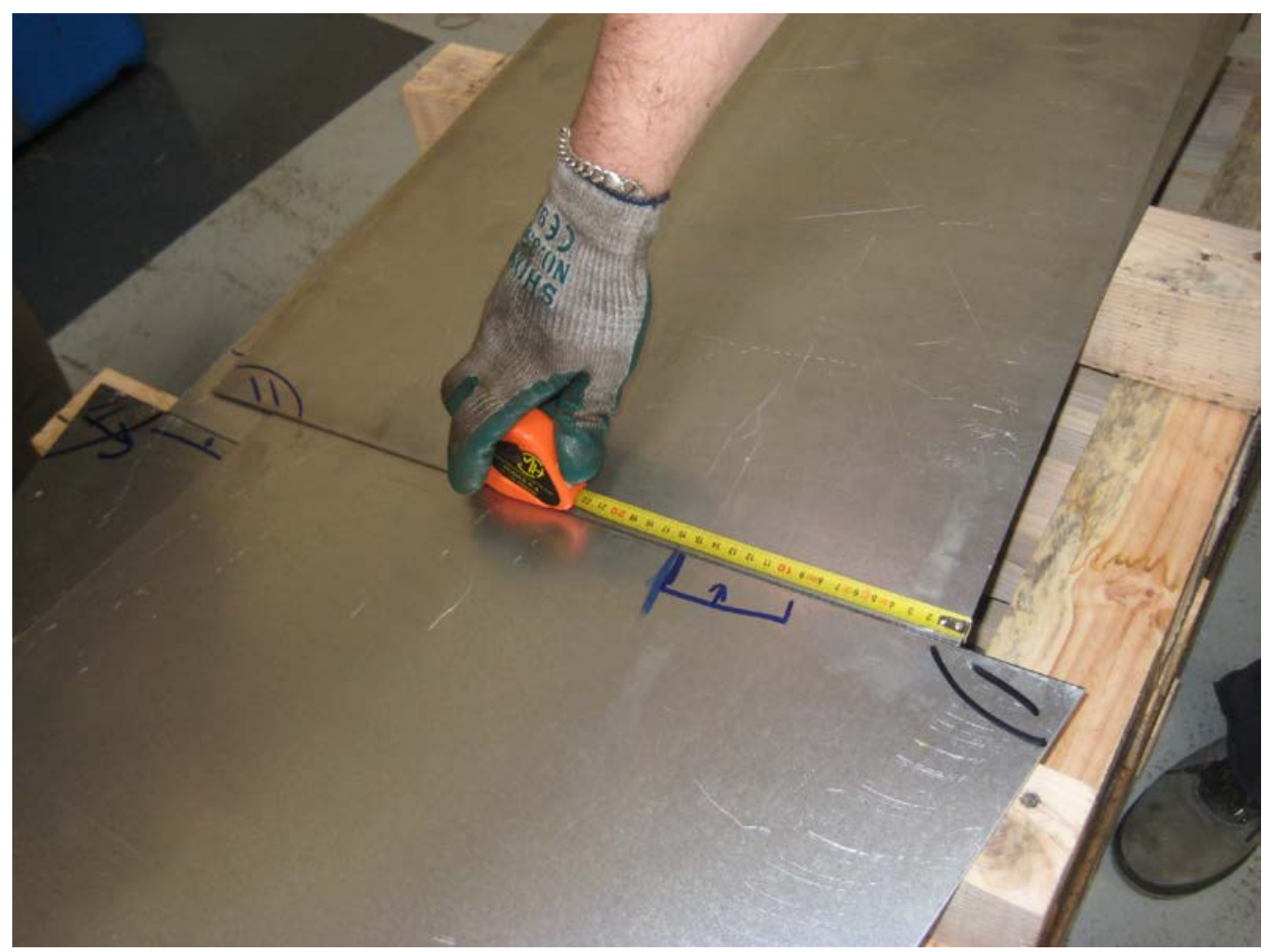

Figure 3. Detail of the Usibor1500 blanks welded during the preliminary tests.

Figure 4 depicts the Al contribution to the plasma plume emission obtained in four tests with different levels of brushing of the sheet joints before welding. The preparation of the Usibor1500 joint for welding implies an initial laser ablation of the joint (of both sheets involved) to remove the $\mathrm{Al} / \mathrm{Si}$ layer. It is difficult to ensure that this layer has been completely removed if an on-line monitoring of the ablation process is not considered. It is important for the welding process to avoid the contribution of $\mathrm{Al}$ in the joint and, in this regard, a second stage involving a mechanical brushing of the sheet joints has also been considered. This mechanical brushing has given rise to the $\mathrm{Al}$ 
contribution depicted with the dotted pink line in Figure 4. It can be observed that this solution implies a reduced $\mathrm{Al}$ contribution in comparison to the other three tests. Following an increasing $\mathrm{Al}$ content, the green profile is associated with manual brushing performed by an operator. The resulting Al contribution is also rather low, but higher than the one obtained via mechanical brushing. The blue dashed line depicts an interesting result, as it is derived from a double brushing procedure. An even more reduced $\mathrm{Al}$ contribution might be expected in the welding process; however, given the small width of the ablated surface (about 3mm from the welding line (Moon et al., 2013)) excessive brushing might lead to heating of the affected area and Al diffusion into the Fe of the ablated region, provoking an unexpected higher $\mathrm{Al}$ contribution.

The thick black line indicates the Al contribution when no brushing is applied before welding. The $\mathrm{Al}$ content profiles have been generated using the ratio of the intensity of the $\mathrm{Al} \mathrm{I}$ line at $396.15 \mathrm{~nm}$ against the adjacent continuum radiation intensity. Figure 5 depicts a comparison among Usibor1500 blanks after a correct brushing process (Figure 5(a)) and after an ineffective brushing (Figure 5(b)). The higher reflectivity of Al can be clearly appreciated in the latter. 


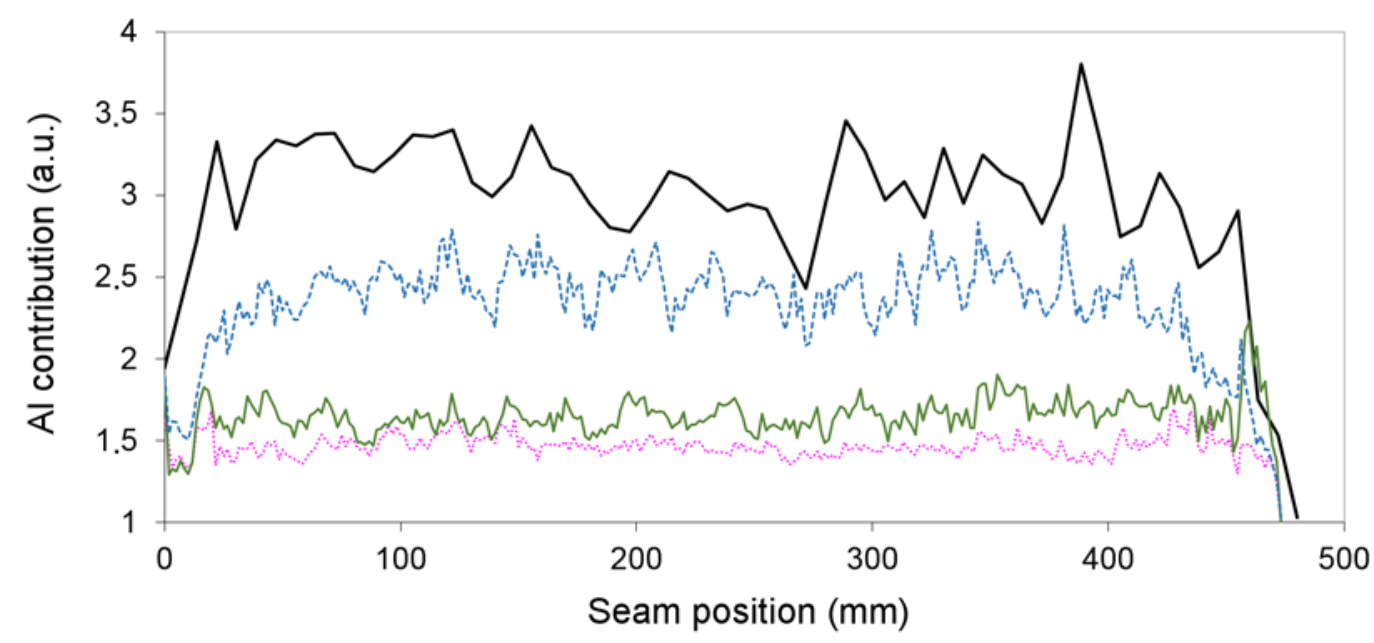

Figure 4. On-line estimation of the $\mathrm{Al}$ contribution in the laser welding process by means of the line-tocontinuum method (Al I 396.15 nm). Usibor1500 blanks without joint brushing (thick black line); Usibor1500 blanks with double joint brushing (blue dashed line); Usibor1500 blanks with manual joint brushing (green line); Usibor1500 blanks with mechanical joint brushing (pink dotted line).

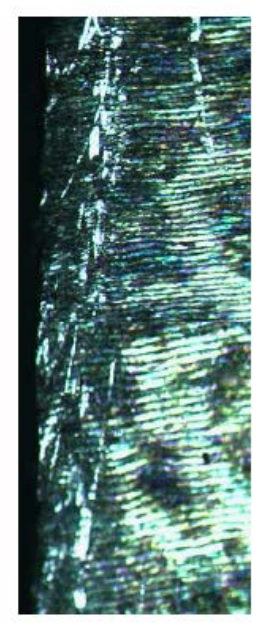

a)

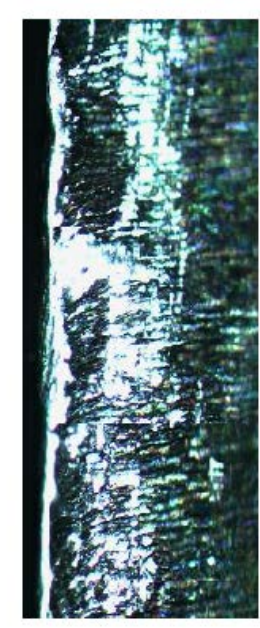

b)

Figure 5. Example of the impact of the brushing process on the Al removal from the joint: (a) Usibor1500 sheet joint after correct brushing; (b) Usibor1500 sheet joint after ineffective brushing.

Apart from merely comparing the contribution of $\mathrm{Al}$ to the welding process by varying the pre-processing of the sheet joint, the influence of the $\mathrm{Al}$ contribution versus the tensile properties and the fracture locations of the associated seams has also been studied. Figure 6 presents an analysis performed in a real production scenario of car part 
manufacturing. Three different seams were studied by comparing the results provided by the spectroscopic monitoring system with tensile tests and macrographs performed in two test specimens per seam (at the beginning and at the end of the seams). The $\mathrm{Al}$ contribution profiles are shown in Figure 6(a), where it can be observed that there is an increase in $\mathrm{Al}$ presence from the blue dotted profile ( $\mathrm{Al}$ average $\approx 0.6)$ to the red dashed one (Al average $\approx 0.8)$ and finally to the black one (Al average $\approx 0.93)$. These profiles are associated with the macrographs of Figures 6(b), 6(c) and 6(d). The high Al content indicated by the black profile is clearly related to the presence of Al highlighted in Figure 6(d), which indicates an unexpected microstructure generated by the presence of Al that avoids austenite being transformed into martensite, remaining as ferrite-pearlite. Both micrographic and hardness (a reduction in the resulting hardness implies the presence of ferrite-pearlite) studies supported this conclusion.
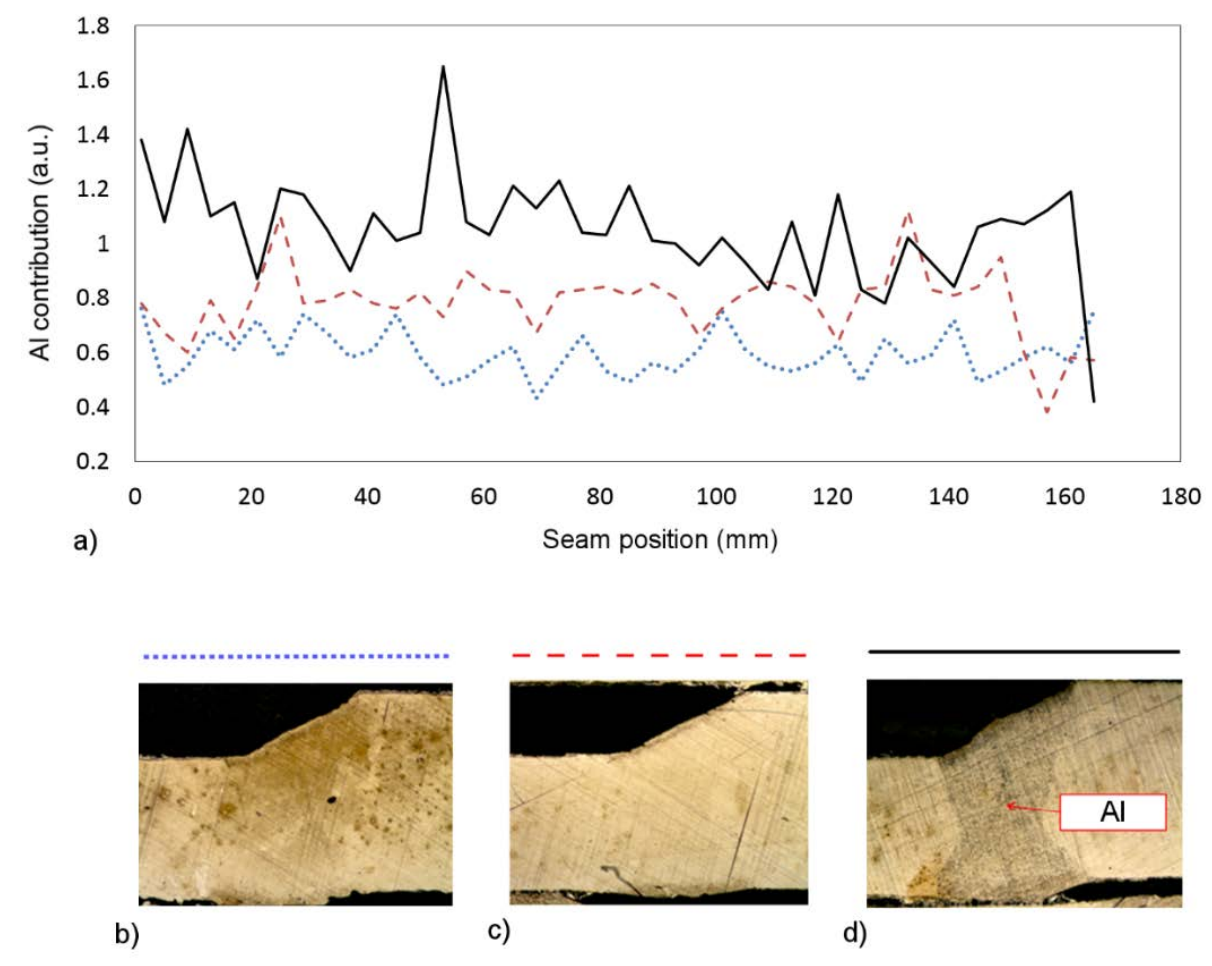

Figure 6. On-line estimation of the $\mathrm{Al}$ contribution during laser welding (real production scenario of car parts) vs. associated macrographs. The blue dotted line is associated with the macrograph in Figure 6(b); the red dashed line is associated with the macrograph in Figure 6(c) and the black line is associated with the macrograph in Figure 6(d). 
Table 2. Data associated with the tests shown in Figure 6

\begin{tabular}{cccccc}
\hline Sp. & Rm (MPa) & Sp. position (mm) & Sp. width $(\mathrm{mm})$ & Al (a.u.) & Seam fracture \\
& & & & & \\
6(b) & 1572 & 25 & 12.5 & 0.65 & No \\
6(b) & 1543 & 105 & 12.5 & 0.6 & Yes \\
6(c) & 1687 & 25 & 12.5 & 0.7 & No \\
6(c) & 1687 & 105 & 12.5 & 0.8 & Yes \\
6(d) & 1640 & 25 & 12.5 & 0.9 & Yes \\
6(d) & 1470 & 105 & 12.5 & 1.1 & Yes \\
\hline
\end{tabular}

Table 3. Data associated with the tests shown in Figure 6 (II)

\begin{tabular}{cccccc}
\hline Sp. & Average Al & $\begin{array}{c}\text { Ab. width } \\
\text { (top) } \\
(\mu \mathrm{m})\end{array}$ & $\begin{array}{c}\text { Ab. width } \\
\text { (bottom) } \\
(\mu \mathrm{m})\end{array}$ & $\begin{array}{c}\text { Seam width } \\
(\text { top) } \\
(\mu \mathrm{m})\end{array}$ & $\begin{array}{c}\text { Seam width } \\
\text { (bottom) } \\
(\mu \mathrm{m})\end{array}$ \\
6(b) & 0.60 & 2084 & 1930 & & \\
6(c) & 0.80 & 1932 & 1880 & 1018 & 1071 \\
6(d) & 1.04 & 1944 & 1821 & 1194 & 1053 \\
& & & & & 975 \\
\hline
\end{tabular}

Results of the tensile tests are reported in Table 2, where a correlation can be deduced between the $\mathrm{Al}$ contribution and the associated results, especially for specimens 6(c) and 6(d). In these cases, the tensile strengths $R_{m}$ and the occurrence of the fracture in the seam seem to be in reasonably good agreement with the average $\mathrm{Al}$ content. The worst scenario in this regard occurs when the fracture during the tensile test appears in the seam, instead of in another area of the specimen away from the joint. Low tensile strengths and fractures in the seam may also be caused by an unsuitable seam geometry provoked by the preparation of the blanks before welding. This may lead to a localized reduction in the seam thickness and to a fracture in the seam at low tensile strengths even in the absence of $\mathrm{Al}$. The results obtained for specimen 6(b), which exhibits fracture in the seam at $105 \mathrm{~mm}$ with a low content of detected $\mathrm{Al}$ (in comparison to the other specimens), may be generated by an unsuitable seam geometry, other defects such 
as porosity (see Figure 6(b)) or the excessive ablation width at the top of the sheet (2084 $\mu \mathrm{m})$.

A final analysis of results derived from production, in this case during the manufacturing of A pillars (right side) (Karbasian and Tekkaya, 2010), structural components of cars, is presented in Fig. 7 and 8. Figure 7 shows the evolution of the $\mathrm{Al}$ contribution (in a.u. in this case multiplied by 800 to provide a better representation) measured in real time during the laser-welding process and the associated $R_{m}$ derived from the tests performed afterwards. There is a clear correlation in $\mathrm{t} \approx 2: 00$, where a high $\mathrm{Al}$ contribution is detected and, consequently, a rather reduced $R_{m}$ is obtained in comparison with the other specimens. The average $R_{m}$ during this production session was $1624 \mathrm{MPa}$, with 28 specimens analysed. In a similar series, where A pillars were also produced, but in this case for the left side of the car, the average $\mathrm{R}_{\mathrm{m}}$ was $1601 \mathrm{MPa}$. These values are in good agreement with values reported in other works (Sharma and Molian, 2011).

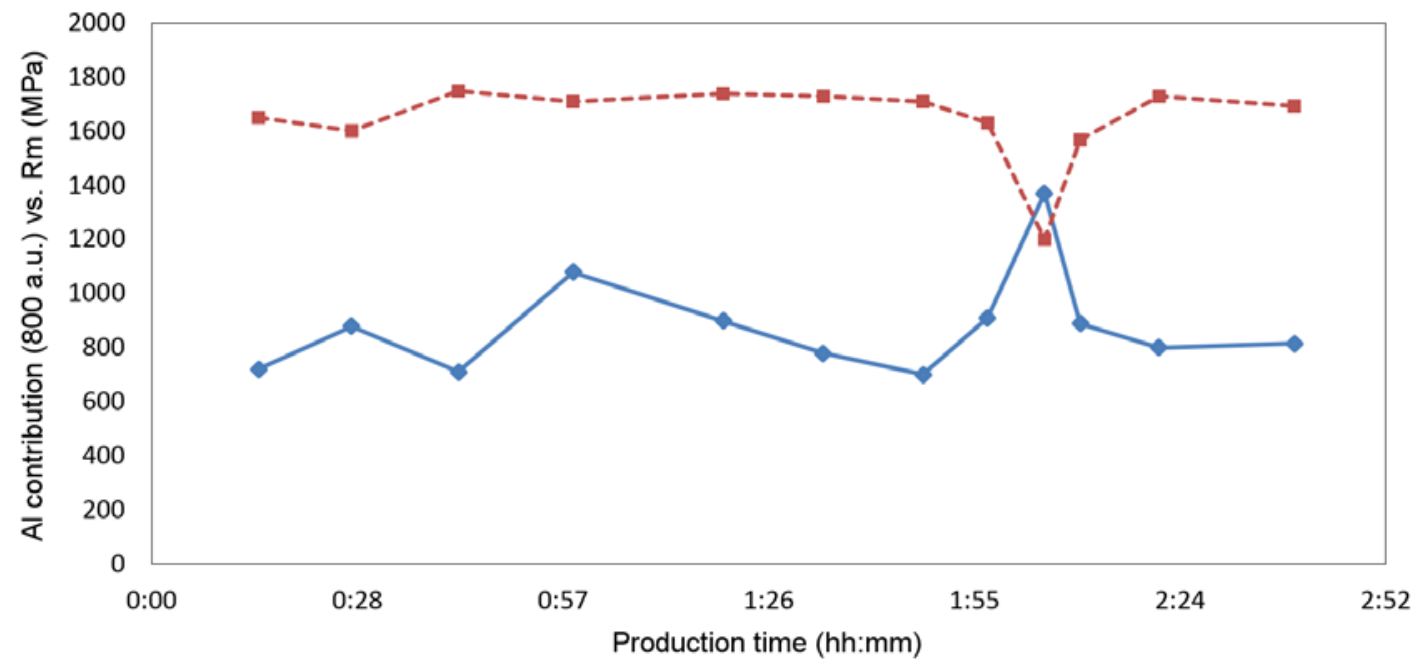

Figure 7. Al contribution (blue line) vs. tensile strength (red dashed line) for a series of seams performed during production in Usibor1500 blanks. 
To ensure that the $\mathrm{Al}$ contribution profile presented in Fig. 7 is reliable, a final study was performed using two Usibor1500 blanks previously ablated to remove the Al-Si coating. A small section of the coating was intentionally left at the end of one of the blanks to evaluate the performance of the proposed system. Fig. 8 shows the resulting line-to-continuum profiles for the selected $\mathrm{Al} \mathrm{I}$ line at $396.15 \mathrm{~nm}$ and also for the Fe I lines at 396.74 and $404.39 \mathrm{~nm}$. The goal of this study was to determine whether the $\mathrm{Al}$ contribution profile presented in Fig. 7 might be affected by variations in the plasma spectra derived from other causes such as the process dynamics or the light collecting system. It can be observed that the Al I line-to-continuum profile (dashed red line) clearly indicates the appearance of $\mathrm{Al}$ at the end of the seam, in agreement with the presence of the coating in that section. The profiles associated with both Fe I lines (black and thick green lines) do not show a significant variation at that location.

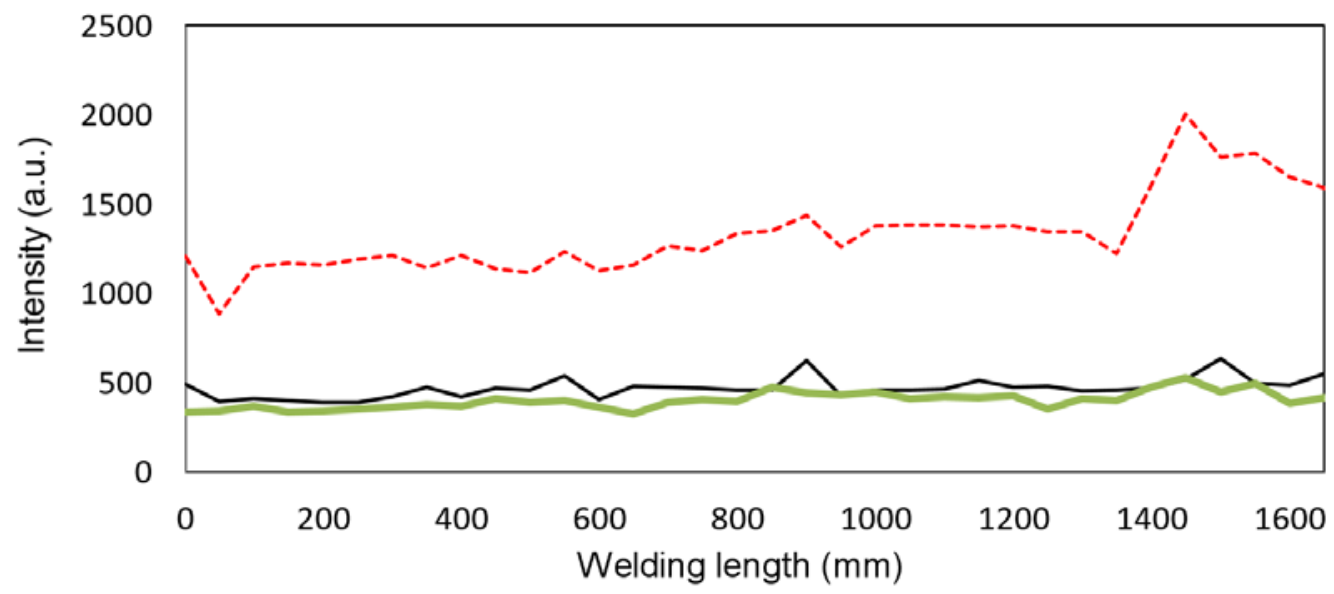

Figure 8. Evolution of the line-to-continuum profiles for two emission lines during laser welding of Usibor1500 blanks: Al I at $396.15 \mathrm{~nm}$ (dashed red line), Fe I at $396.74 \mathrm{~nm}$ (black line) and Fe I at 404.39 nm (thick green line). The Al-Si coating was removed by laser ablation, leaving a small coated section at the end of the joint. 


\section{Conclusions}

The contribution of $\mathrm{Al}$ during laser welding of Usibor1500 blanks has been detected in real time in this work by means of a plasma spectroscopy approach. The relevance of the brushing process previous to the welding of the blanks has been demonstrated in terms of the $\mathrm{Al}$ to be found in the joint. The $\mathrm{Al}$ contribution measured on-line has been correlated with off-line analyses such as macrographs or tensile tests performed on specimens derived from both experimental tests and real production data.

It has been concluded that the $\mathrm{Al}$ contribution estimated in real time in the welding process is directly related to the resulting $\mathrm{Al}$ in the seam, for example, for different levels of brushing. A correlation has been established between the $\mathrm{Al}$ contribution and the tensile tests (a higher $\mathrm{Al}$ contribution gives rise to lower tensile strengths) with data obtained in a real production scenario during the welding of the A pillars for a specific car model. Although for very high Al contributions a correlation with fractures produced in the specimen seam has been identified, for lower $\mathrm{Al}$ contents this situation is not so clear. Further studies should be carried out in order to develop a better correlation and a more sophisticated model and to better understand other possible causes affecting the tensile tests, such as the influence of the seam geometry.

The possibility of measuring in real time the Al contribution during the welding of Usibor1500 tailor-welded blanks might be of great significance for the automotive industry, reducing the necessity of expensive off-line evaluations, and so enabling realtime control of the production line (for example discarding those seams with an $\mathrm{Al}$ contribution over a given threshold). This will enable better understanding of the whole process and of the effectiveness of the measures considered to eliminate the $\mathrm{Al}$ cover from the Usibor blanks. 
This proposal might also be explored for the monitoring of the ablation process itself, thus providing information in advance about the $\mathrm{Al}$ contribution along the sheet joint. Future work will show that the occurrence of defects such as misalignments or discontinuities in the seam should be considered by implementing strategies to avoid an incorrect Al estimation. The feasibility of performing a validation of the spectroscopic estimation of $\mathrm{Al}$ contribution will also be explored by performing an element analysis of the seam via LIBS (Laser Induced Breakdown Spectroscopy).

\section{Acknowledgments}

The authors would like to thank the staff of Autotech Engineering and Solblank (both Gestamp companies) for their valuable help during the design, implementation and test of the monitoring system. This work has been supported by the project TEC201347264-C2-1-R.

\section{References}

Abdullah, B., Smith, J., Lucas, W., Lucas, J., Malek, F., 2008. Monitoring of TIG welding using laser and diode illumination sources: a comparison study, Electronic Design, 2008. ICED 2008. International Conference on. IEEE, pp. 1-4.

Aguilera, J., Aragon, C., 2002. Temperature and electron density distributions of laserinduced plasmas generated with an iron sample at different ambient gas pressures. Applied surface science 197, 273-280.

Amato, G., Cristoforetti, G., Legnaioli, S., Lorenzetti, G., Palleschi, V., Sorrentino, F., Tognoni, E., 2010. Progress towards an unassisted element identification from Laser Induced Breakdown Spectra with automatic ranking techniques inspired by text retrieval. Spectrochimica Acta Part B: Atomic Spectroscopy 65, 664-670.

Anabitarte, F., Mirapeix, J., Portilla, O.M.C., Lopez-Higuera, J.M., Cobo, A., 2012. Sensor for the Detection of Protective Coating Traces on Boron Steel With AluminiumSilicon Covering by Means of Laser-Induced Breakdown Spectroscopy and Support Vector Machines. Sensors Journal, IEEE 12, 64-70.

Ancona, A., Spagnolo, V., Lugara, P.M., Ferrara, M., 2001. Optical Sensor for real-time Monitoring of CO2 Laser Welding Process. Applied Optics 40, 6019-6025. 
Aragon, C., Bengoechea, J., Aguilera, J., 2001. Influence of the optical depth on spectral line emission from laser-induced plasmas. Spectrochimica Acta Part B: Atomic Spectroscopy 56, 619-628.

Chandrasekhar, N., Vasudevan, M., Bhaduri, A., Jayakumar, T., 2015. Intelligent modeling for estimating weld bead width and depth of penetration from infra-red thermal images of the weld pool. Journal of Intelligent Manufacturing 26, 59-71.

Ferrara, M., Ancona, A., Lugara, P.M., Sibilano, M., 2000. Online quality monitoring of welding processes by means of plasma optical spectroscopy, Advanced High-Power Lasers and Applications. International Society for Optics and Photonics, pp. 750-758.

Garcia-Allende, P.B., Mirapeix, J., Conde, O.M., Cobo, A., Lopez-Higuera, J.M., 2009. Defect detection in arc-welding processes by means of the line-to-continuum method and feature selection. Sensors 9, 7753-7770.

Gornushkin, I., Panne, U., Winefordner, J., 2009. Linear correlation for identification of materials by laser induced breakdown spectroscopy: Improvement via spectral filtering and masking. Spectrochimica Acta Part B: Atomic Spectroscopy 64, 1040-1047.

Gu, H., Duley, W., 1996. A statistical approach to acoustic monitoring of laser welding. Journal of Physics D: Applied Physics 29, 556.

Güler, H., 2013. Investigation of Usibor 1500 Formability in a Hot Forming Operation. Materials Science 19, 144-146.

Harooni, M., Carlson, B., Kovacevic, R., 2014. Detection of defects in laser welding of AZ31B magnesium alloy in zero-gap lap joint configuration by a real-time spectroscopic analysis. Optics and Lasers in Engineering 56, 54-66.

Jamrozik, W., Fidali, M., Bzymek, A., Timofiejczuk, A., 2015. Application of fused visual and thermal images in monitoring and evaluation of welding processes. Welding International 29, 445-453.

Kang, M., Kim, C., Lee, J., 2012. Weld strength of laser-welded hot-press-forming steel. Journal of Laser Applications 24, 022004.

Karbasian, H., Tekkaya, A.E., 2010. A review on hot stamping. Journal of Materials Processing Technology 210, 2103-2118.

Kong, F., Ma, J., Carlson, B., Kovacevic, R., 2012. Real-time monitoring of laser welding of galvanized high strength steel in lap joint configuration. Optics \& Laser Technology 44, 2186-2196.

Kramida, A., Ralchenko, Y., Reader, J., 2012. NIST atomic spectra database (ver. 5.0). National Institute of Standards and Technology, Gaithersburg, MD.

Kusumi, K., Ohgami, M., Miyakoshi, T., 2003. Properties of Aluminum-coated Steels for Hot-forming. Nippon Steel Technical Report.

Lee, M., Moon, J., Kang, C., 2014. Effect of the Die Temperature and Blank Thickness on the Formability of a Laser-Welded Blank of a Boron Steel Sheet with Removing AlSi Coating Layer. Advances in Mechanical Engineering 6, 925493.

Merklein, M., Wieland, M., Lechner, M., Bruschi, S., Ghiotti, A., 2015. Hot Stamping of Boron Steel Sheets with Tailored Properties: a Review. Journal of Materials Processing Technology.

Lacroix, D., Boudot, C., Jeandel, G., 1999. Spectroscopic studies of GTA welding plasmas. Temperature calculation and dilution measurement. The European Physical Journal Applied Physics 8, 61-69.

Mirapeix, J., Cobo, A., Fernandez, S., Cardoso, R., Lopez-Higuera, J., 2008. Spectroscopic analysis of the plasma continuum radiation for on-line arc-welding defect detection. Journal of Physics D: Applied Physics 41, 135202. 
Mirapeix, J., Ruiz Lombera, R., Valdiande, J.J., Lopez-Higuera, J.M., 2014. Colorimetric analysis for on-line arc-welding diagnostics by means of plasma optical spectroscopy, SENSORS, 2014 IEEE. IEEE, pp. 637-640.

Moon, J.-H., Seo, P.-K., Kang, C.-G., 2013. A study on mechanical properties of laserwelded blank of a boron sheet steel by laser ablation variable of Al-Si coating layer. International Journal of Precision Engineering and Manufacturing 14, 283-288.

Norman, P., Wiklund, G., Janiak, P., Malmberg, N., Kaplan, A., 2011. Comparison of 22MnB5-steel with and without AlSi-coating during laser hybrid arc welding, 13th NOLAMP Conference: 13th Conference on Laser Materials Processing in the Nordic Countries 27-29 June 2011. Trondheim: Norwegian University of Science and Technology.

Šebestová, H., 2012. Spectroscopic monitoring of penetration depth in CO 2 Nd: YAG and fiber laser welding processes. Journal of Materials Processing Technology 212, 910-916.

Sharma, R.S., Molian, P., 2011. Weldability of advanced high strength steels using an Yb: YAG disk laser. Journal of Materials Processing Technology 211, 1888-1897.

Sibillano, T., Rizzi, D., Ancona, A., Saludes-Rodil, S., Nieto, J.R., Chmelíčková, H., Speka, M., Matteï, S., Pilloz, M., Ilie, M., 2008. The infrared thermography control of the laser welding of amorphous polymers. NDT \& E International 41, 178-183.

Sreedhar, U., Krishnamurthy, C., Balasubramaniam, K., Raghupathy, V., Ravisankar, S., 2012. Automatic defect identification using thermal image analysis for online weld quality monitoring. Journal of Materials Processing Technology 212, 1557-1566.

Sumesh, A., Rameshkumar, K., Mohandas, K., Babu, R.S., 2015. Use of Machine Learning Algorithms for Weld Quality Monitoring using Acoustic Signature. Procedia Computer Science 50, 316-322.

Zhang, G., Wu, C.S., Liu, X., 2015. Single vision system for simultaneous observation of keyhole and weld pool in plasma arc welding. Journal of Materials Processing Technology 215, 71-78.

Zhang, Z., Chen, X., Chen, H., Zhong, J., Chen, S., 2014. Online welding quality monitoring based on feature extraction of arc voltage signal. The International Journal of Advanced Manufacturing Technology 70, 1661-1671.

Zhang, Z., Yu, H., Lv, N., Chen, S., 2013. Real-time defect detection in pulsed GTAW of $\mathrm{Al}$ alloys through on-line spectroscopy. Journal of Materials Processing Technology 213, 1146-1156. 